\title{
Karakteristik Iklim Mikro Serta Pertumbuhan Pada Beberapa Sistem Tanam Jagung Dengan Pola Tanam Tumpang Sari Dan Tanam Tunggal
}

\section{Micro Climate Characteristics and Growth in Several Corn Planting Systems With Polikulture and Monokulture Partern}

\author{
Risa Wentasari dan Adriyade Reshi Gusta ${ }^{2}$ \\ ${ }^{1}$ Jurusan Budidaya Tanaman Pangan, Politeknik Negeri Lampung \\ ${ }^{2}$ Jurusan Tanaman Perkebunan Politeknik Negeri Lampung \\ Jl. Soekarno Hatta No 10 Rajabasa Bandar Lampung \\ Email : wenta_risa@yahoo.com
}

\begin{abstract}
The purpose of this study is to know the characteristics of microclimate and the growth of corn and soybean on single row, doble row, twin row, and twin row seed system in policulture and monoculture pattern. The research was arranged in Randomized Block Design with two factors (1) planting system consisting of 4 treatments (Sigle Row (SR) (25x $75 \mathrm{~cm})$ Doble Row (DR) (20x 20x 80cm), Twin Row (TR) (20x10x $80 \mathrm{~cm})$, and Twin Seed (TS) (40 $\times 75 \mathrm{~cm}$ (2 seed in 1 planting hole)) and (2) Cropping Pattern (Polikulture (TS) (100 cm of corn line distance)) and monokulture (TT), with 3 replications. Data analysis was done by F test (1\% and 5\%) and BNT (5\%). Conclusions: Microclimatic characteristics (a) Light Interception (\%) at morning of middle plant canopy, midday and afternoon in the middle and lower part of the canopy are not significantly different. There is a significant difference in morning light interception at the bottom of the plant canopy, the lowest light interception is TTSR treatment. Temperature $\left({ }^{\circ} \mathrm{C}\right)$ there was significant difference of temperature due to treatment. the TTTS treatment had the highest average temperature under the plant canopy $\left(26.30^{\circ} \mathrm{C}\right)$ and the center of the plant canopy $\left(29.40^{\circ} \mathrm{C}\right)$. Relative humidity $(\%)$ did not give a significantly different response to the treatment.
\end{abstract}

Keywords: microclimate, growth, cropping system, cropping pattern

Disubmit : 12 Juni 2018; Diterima: 17 Juli 2018; Disetujui : 16 September 2018;

\section{PENDAHULUAN}

Pengaturan pola tanam bertujuan untuk menciptakan iklim mikro yang sesuai untuk pertumbuhan tanaman. Sistem tanam pada tanaman akan berpengaruh pada kerapatan populasi tanaman. Populasi tanaman menyebabkan perebutan kebutuhan hidup antar individu, baik ruang antau sumberdaya lain. Sehingga tercipta iklim yang khas pada satu populasi tanaman yang sering disebut iklim mikro.

Iklim mikro merupakan iklim dilapisan udara dekat permukaan bumi dengan ketinggian \pm 2 meter, dimana pada daerah ini gerak udara lebih kecil karena permukaan bumi kasar dan perbedaan suhu yang besar. Keadaan tanaman dapat mengakibatkan perlawanan iklim yang besar dalam ruang yang sempit. Iklim mikro meliputi suhu, kelembaban dan cahaya (Bunyamin. Z dan Aqil, 2010)

Hasil penelitian Sesanti Rizka Novi et al., (2014) mengenai sistem tanam jagung manis Dua Baris (DB) dengan jarak tanam $80 \mathrm{~cm} \times 20 \mathrm{~cm} \times 20 \mathrm{~cm}$ dan satu baris $20 \mathrm{~cm}$ x $75 \mathrm{~cm}$ menunjukkan bahwa nilai ratarata bobot tongkol dengan kelobot pada pola tanam SB sangat tinggi (642 g), sedangkan nilai rata-rata bobot tongkol dengan kelobot pada pola tanam DB rendah yaitu 319 g. namun demikian nilai rata-rata bobot 
tongkol tanpa kelobot pada pola tanam SB dan DB tidak berbeda yaitu 274,50 g dan 236,75 g.namun demikian, dari hasil tersebut diketahui bahwa budidaya jagung manis dengan pola tanam DB dapat meningkatkan hasil panen akibat penambahan jumlah populasi tanaman jagung manis per satuan luas.

Hal ini sejalan dengan hasil penelitian Wentasari dan Sesanti, (2017), dimana peningkatan populasi melalui berbagai sistem tanam jagung manis Sigle Row $(20 \mathrm{~cm} \times 75 \mathrm{~cm})$, Doble Row $(20 \mathrm{~cm} \times 20 \mathrm{~cm} \times 80 \mathrm{~cm})$, Twins Row $(20 \mathrm{~cm} \times 10 \mathrm{~cm} \times 80 \mathrm{~cm})$, dan Twins Seed $(40 \mathrm{~cm} \times 75 \mathrm{~cm}$ dengan 2 benih per lubang tanam) tidak berbeda nyata dalam parameter produksi. Sehingga sistem tanam Doble Row, Twins Row, dan Twins Seed dapat dijadikan sistem tanam alternatif dalam peningkatan produksi per satuan luas.

Secara umum pola tanam tumpang sari jagung dengan kacang kacangan, akan mengurangi populasi jagung, karena jarak lorong akan diperbesar untuk tanaman kacang kacangan. Sehingga hasil jagung akan menjadi lebih rendah dibandingkan dengan pola tanam tunggal. Oleh karena itu penerapan sistem tanam jagung dengan populasi tinggi Doble Row, Twins Row, dan Twins Seed pada pola tanam tumpang sari diharapkan akan meminimalisis kehilangan populasi akibat lorong yang diperlebar, pada akhirnya akan meningkatakan produktifitas jagung pada pola tanam tumpang sari tersebut.

Untuk mengetahui efektifitas sistem tanam jagung tersebut pada pola tumpang sari dengan kedelai diperlukan pengkajian tentang iklim mikro yang dihasilkan oleh sistem tanam jagung pada pola tanam tumpang sari dengan kedelau yang diterapkan sehingga diketahui sistem tanam jagung pada pola tanam tumpang sari manakah yang memiliki iklim mikro yang ideal bagi pertumbuhan tanaman yang akhirnya berpengaruh pada produktifitas tanaman.

Tujuan penelitian ini adalah (1) mengetahui karakteristik iklim mikro meliputi : suhu, kelembaban, dan persen intersepsi cahaya pada sistem tanam sigle row, doble row, twin row, dan Twin seed pada pola tanam tumpangsari dan tanam tunggal dan (2) mengetahui pertumbuhan jagung dan kedelai pada sistem tanam sigle row, doble row, twin row, dan Twin seed pada pola tanam tumpang sari dan tanam tunggal.

\section{METODE PENELITIAN}

Penelitian ini akan dilakukan di kebun percobaan Politeknik Negeri Lampung, pada bulan April Oktober 2017; Alat yang digunakan dalam penelitian ini : Alat budidaya secara umum (cangkul, kored, sprayer, ember, dll), Light meter, hygro termometer, meteran, dan jangka sorong. Bahan : Benih Jagung manis, Pupuk (Urea, SP36, KCl), Pestisida, Herbisida. Penelitian ini disusun berdasarkan Rancangan Acak Kelompok dengan dua faktor (1) sistem tanam terdiri dari 4 perlakuan yaitu : Sigle Row (SR) Jarak Tanam $20 \mathrm{~cm}$ x 75cm, Doble Row (DR) Jarak Tanam $20 \mathrm{~cm}$ x $20 \mathrm{~cm}$ x $80 \mathrm{~cm}$, Twin Row (TR) $20 \mathrm{~cm}$ x $10 \mathrm{~cm}$ x 80 $\mathrm{cm}$, dan Twin Seed (TS) Jarak Tanam $40 \mathrm{~cm} \times 75 \mathrm{~cm} 2$ benih perlubang tanam.dan (2) Pola Tanam : Tumpang Sari (TS) dan Tanam Tunggal (TT) dengan jarak antar baris jagung $100 \mathrm{~cm}$, sehingga diperoleh 8 kombinasi perlakuan. Masing-masing perlakuan terdiri dari 3 Ulangan maka didapatkan 27 plot percobaan.

\section{Tahapan Penelitian}

Persiapan Lahan, dilakukan pengolahan lahan dengan cara dibajak dan digaru dengan menggunakan hand traktor dan kemudian dilakukan membutan plot percobaan dengan ukuran 5 x 2 m sebanyak 27 plot percobaan.

Penanaman, Penanaman dilakukan dengan cara membuat lubang tanam dengan kedalaman $\pm 5 \mathrm{~cm}$. Kemudian dilakukan penanaman sesuai dengan jarak tanam sesuai dengan perlakuan Sigle Row (SR), Doble Row (DR) dan Twin Row (TR) dilakukan penanaman 1 benih/lubang, dan Untuk Twin Seed (TS) dilakukan 2 benih/lubang dan tanaman kedelai dengan jarak $25 \mathrm{~cm}$ x $25 \mathrm{~cm}$ pada pola tanam multiple cropping.

Pemeliharaan, meliputi kegiatan penyulaman, Penyiangan, Pengairan, Pemupukan, pengendalian hama dan penyakit, pemupukan dengan dosis acuan yang digunakan $300 \mathrm{~kg}$ Urea/Ha, $100 \mathrm{~kg}$ SP36/Ha dan $100 \mathrm{~kg} \mathrm{KCl} / \mathrm{ha}$. Pemupukan dilakukan 3 kali yaitu : Pemupukan I, dilakukan 7 hari Setelah Tanam (HST) 
terdiri dari Urea 1/3 dosis, SP36, dan $\mathrm{KCl}$, Pemupukan II, dilakukan 28-30 HST pemberian pupuk Urea 1/3 dosis, dan pemupukan III, 45-50 HST pemberian pupuk Urea 1/3 dosis.

Panen, dilakukan pada saat tanaman berumur 70-75 hari setelah tanam. Dengan kriteria kelobot sudah berubah warna agak kekuningan, tongkol jagung berisi penuh dan agak keras, serta warna rambut jagung yang sudah berwarna coklat kehitaman.

Pengamatan, parameter pengamatan terdiri dari :

1. Parameter Iklim Mikro meliputi :

a. Suhu udara $\left({ }^{\circ} \mathrm{C}\right)$, Pengukuran dilakukan dengan menggunakan termometer bola kering, pada 3 waktu pengamatan yaitu : $7.30,12.30$, dan 17.30 , suhu rata-rata diperoleh dengan perhitungan berdasarkan (Handoko, 1993)sebagai berikut :

$$
\mathrm{T}(\text { rata }- \text { rata })=\frac{2 . \mathrm{T} 7.30+\mathrm{T} 12.30+\mathrm{T} 17.30}{4}
$$

b. Kelembaban (\%), Pengukuran dilakukan dengan mengunakan psikometer yang diamati 3 waktu pengamatan yaitu: 7.30, 12.30, dan 17.30. Kelembaban Rata-Rata (RH) dapat dihitung dengan persamaan berikut ini :

$$
\mathrm{RH}(\text { rata }- \text { rata })=\frac{\mathrm{RH} 7.30+\mathrm{RH} 12.30+\mathrm{RH} 17.30}{3}
$$

Untuk Suhu udara $\left({ }^{\circ} \mathrm{C}\right)$ dan Kelembaban $(\%)$ dilakukan pengamatan bagian tengah dan bawah kanopi tanaman

c. Intersepsi Cahaya (\%), Pengukuran dilakukan dengan menggunakan light meter, pada pukul 7.30 , 12.30 dan 17.30. Intersepsi Cahaya (\%) dihitung dengan persamaan:

$$
\text { Intersepsi Cahaya }(\%)=\frac{\text { Jumlah cahaya yang diterima diatas kanopi tanaman }}{\text { Jumlah Cahaya yang diterima di bawah kanopi tanaman }} \times 100 \%
$$

Untuk semua parameter iklim mikro 5 menit untuk setiap titik pengambilan data, dengan memindahkan alat dari petak ke petak.

2. Parameter Pertumbuhan

Pengamatan pertumbuhan tanaman dilakukan dengan menentukan 5 sampel pada setiap petak percobaan pada saat pertumbuhan vegetatif akhir tanaman jagung ditandai dengan telah munculnya bunga jantan tanaman jagung. Parameter pengamatan vegetatif pada jagung dan kedelai sebagai berikut :

\section{Jagung}

a. Tinggi tanaman $(\mathrm{cm})$, diamati dengan cara mengukur dengan pengaris dari pangkal batang sampai ujung daun tertinggi

b. Diameter batang $(\mathrm{cm})$, mengukur bagian tengah batang dengan menggunakan jangka sorong

c. Lebar Daun $(\mathrm{cm})$, diamati dengan cara mengukur lebar daun bagian daun terlebar dari sisi kanan dan kiri daun dengan mistar pengukur.

d. Jumlah daun (helai), diamati dengan cara menghitung semua daun yang ada dari pangkal sampai ujung tanaman.

\section{Kedelai}

a. Tinggi Tanaman $(\mathrm{cm})$, diukur mulai dari pangkal batang sampai ke titik tumbuh dengan menggunakan mistar pengukur. Pengamatan dimulai dari 3 minggu setelah tanam sampai 10 minggu setelah tanam 
b. Jumlah Cabang (cabang), pengamatan cabang dilakukan dengan menghitung cabang utama (cabang primer) yang terbentuk pada batang tanaman, pengamatan dilakukan pada saat panen

c. Jumlah Cabang Produktif (Cabang), pengamatan dilakukan dengan menghitung cabang yang menghasilkan polong, dilakukan pada saat panen.

Analisis Data, data hasil penelitian dari tiap parameter pengamatan dilakukan analisis dengan menggunakan uji $\mathrm{F}$ pada taraf kesalahn $1 \%$ dan 5\%. Jika terdapat berbedaan nyata pada uji $\mathrm{F}$ maka dilakukan uji lanjut BNT.

\section{HASIL DAN PEMBAHASAN}

Karakteristik Iklim Mikro. Sistem pertanaman akan menciptakan kondisi lingkungan yang khas yang merupakan interaksi antar satu individu tanaman dengan indivudu tanaman lain maupun interaksi tanaman dengan lingkungannya. Kondisi lingkungan yang khas ini yang akan berpengaruh pada pertumbuhan dan perkembangan tanaman. Unsur iklim yang sangat berpengaruh pada pertumbuhan tanaman adalah cahaya matahari, suhu dan kelembaban.

Intersepsi Cahaya merupakan persentase jumlah cahaya matahari yang sampai pada pertanaman. Hasil sidik ragam secara umum menunjukkan bahwa intersepsi cahaya pada perlakuan tidak berbeda nyata, hanya terdapat perbedaan nyata pada intersepsi cahaya pagi hari bagian bawah tanaman (Tabel 1).

Tabel 1. Hasil Sidik Ragam Intersepsi Cahaya

\begin{tabular}{|c|c|c|c|c|c|c|}
\hline \multirow{3}{*}{ Perlakuan } & \multicolumn{6}{|c|}{ Intersepsi Cahaya (\%) } \\
\hline & \multicolumn{2}{|c|}{ Pagi } & \multicolumn{2}{|c|}{ Siang } & \multicolumn{2}{|c|}{ Sore } \\
\hline & Bawah & Tengah & Bawah & Tengah & Bawah & Tengah \\
\hline \multicolumn{7}{|l|}{ Tanam Tunggal } \\
\hline Sigle Row & $22.33 \quad \mathbf{b}$ & $28,07 \mathbf{a}$ & $28,07 \mathbf{a}$ & $28,30 \mathbf{a}$ & $28,23 \mathbf{a}$ & $28,23 \mathbf{a}$ \\
\hline Doble Row & $24,33 \mathbf{a b}$ & $28,87 \mathbf{a}$ & $28,80 \mathbf{a}$ & $29,10 \mathbf{a}$ & $28,93 \mathbf{a}$ & $29,07 \mathbf{a}$ \\
\hline Twins Row & $23,93 \mathbf{a b}$ & $29,07 \mathbf{a}$ & $29,10 \mathbf{a}$ & $29,20 \mathbf{a}$ & $29,03 \mathbf{a}$ & $29,07 \mathbf{a}$ \\
\hline Twins Seeds & $25,53 \mathbf{a}$ & $29,00 \mathbf{a}$ & $29,03 \mathbf{a}$ & $28,30 \mathbf{a}$ & $28,27 \mathbf{a}$ & $28,13 \mathbf{a}$ \\
\hline Kedelai & $24,90 \mathbf{a}$ & $28,80 \mathbf{a}$ & $28,90 \mathbf{a}$ & 29,10 a & $29,14 \mathbf{a}$ & $29,13 \mathbf{a}$ \\
\hline \multicolumn{7}{|l|}{ Tumpangsari } \\
\hline Sigle Row & $24,50 \mathbf{a}$ & $28,23 \mathbf{a}$ & $28,40 \mathbf{a}$ & $28,03 \mathbf{a}$ & $28,00 \mathbf{a}$ & $28,03 \mathbf{a}$ \\
\hline Doble Row & 23,50 ab & $28,37 \mathbf{a}$ & $28,57 \mathbf{a}$ & $27,60 \mathbf{a}$ & $27,60 \mathbf{a}$ & $27,53 \mathbf{a}$ \\
\hline Twins Row & $24,13 \mathbf{a b}$ & $28,50 \mathbf{a}$ & $28,67 \mathbf{a}$ & $29,20 \mathbf{a}$ & $29,23 \mathbf{a}$ & $29,23 \mathbf{a}$ \\
\hline Twins Seeds & $23,47 \mathbf{a b}$ & $28,00 \mathbf{a}$ & $27,90 \mathbf{a}$ & $28,40 \mathbf{a}$ & $28,47 \mathbf{a}$ & $27,70 \mathbf{a}$ \\
\hline Respon & $*$ & tn & tn & tn & tn & tn \\
\hline
\end{tabular}

Keterangan : $\operatorname{tn}=$ tidak nyata, ${ }^{*}=$ nyata pada taraf $5 \%, * *=$ nyata pada taraf $1 \%$. Angka yang diikuti dengan huruf sama tidak menunjukkan perbedaan nyata pada uji BNT $5 \%$.

Berdasarkan uji lanjut BNT $5 \%$ menunjukkan bahwa terdapat perbedaan nyata antara perlakuan tanam tunggal sigle row $(22,33 \%)$ dengan tumpangsari sigle row $(24,50 \%)$, tanam tungg tunggal twins seed $(25,53 \%)$ dan kedelai $(24,90 \%)$. hal ini diduga disebabkan oleh jumlah populasi pada tanam tunggal sigle row memiliki populasi jagung lebih tinggi (70 tanaman jagung) dibandingkan pada tumpangsari sigle row dan twins seed (50 tanaman jagung) dan tanam tunggal kedelai tanpa naungan jagung. Sejalan dengan hasil penelitian Indrawan, et al (2017), bahwa perlakuan sistem tanam 3 benih per lubang pada tanam konvensional dan jajar legowo memiliki intensitas cahaya yang lebih rendah dibandingkan dengan perlakuan sistem tanam 1 benih dan 2 benih per lubang. Hal ini disebabkan radiasi matahari yang masuk kedalam tajuk tanaman mengalami penurunan akibat kanopi yang padat.

Jumlah populasi jagung yang sama pada tanam tunggal sigle row dan twins seed tidak menyebabkan perbedaan nyata pada intersepsi cahaya dipagi hari. Hal ini diduga disebabkan oleh jarak antar tanaman dalam baris tanam tunggal memiliki jarak tanaman dalam baris dan jarak tanaman antar baris lebih rapat (20 
x75 cm) dibandingkan dengan tanam tunggal twins seeds $(40$ x $75 \mathrm{~cm})$. Menurut Slamet B, (2008), bahwa faktor yang mempengaruhi ketersediaan cahaya adalah faktor lahan dan vegetasinya dimana tinggi dan kerapatan populasi daun dalam kanopi mempengaruhi jumlah cahaya yang masuk.semakin rapat populasi maka cahaya masuk akan menurun.

Suhu Harian $\left({ }^{\circ} \mathbf{C}\right)$ Hasil sidik ragam menunjukkan bahwa parameter suhu memberikan respon sangat nyata pada perlakuan dan hasil uji lanjut BNT (5\%) menunjukkan bahwa terdapat perbedaan nyata antar perlakuan. Perlakuan tumpangsari twins seed memiliki rata-rata suhu yang tertinggi dibagian bawah tajuk tanaman $\left(26.30{ }^{\circ} \mathrm{C}\right)$ dan dibagian tengah tajuk tanaman $\left(29,40{ }^{\circ} \mathrm{C}\right)$. Hal ini diduga disebabkan oleh kerapatan populasi tumpangsari twins seeds, dimana perlakuan ini memiliki populasi tertinggi yaitu 102 tanaman jagung dan 80 tanaman kedelai atau dengan total 182 tanaman. Menurut Tjasyono, (2004) bahwa suhu udara didalam gedung lebih tinggi dibandingkan di luar gedung. Hal ini sejalan dengan hal diatas bahwa dengan kerapatan populasi yang tinggi maka suhu dalam tajuk akan semakin tinggi dibandingkan pada populasi dengan kerapatan rendah.

Tabel 2. Hasil Sidik Ragam Parameter Suhu Harian $\left({ }^{\circ} \mathrm{C}\right)$ dan Kelembaban Udara Harian $(\%)$

\begin{tabular}{|c|c|c|c|c|}
\hline \multirow[t]{2}{*}{ Perlakuan } & \multicolumn{2}{|c|}{ SUHU $\left({ }^{\circ} \mathrm{C}\right)$} & \multicolumn{2}{|c|}{ KELEMBABAN (\%) } \\
\hline & Bawah & Tengah & Bawah & Tengah \\
\hline Tanam Tunggal & & & & \\
\hline Sigle Row & 23,97 bcd & $29,10 \mathbf{a b}$ & $65,47 \mathbf{a}$ & $67,33 \mathbf{a}$ \\
\hline Doble Row & $22,30 \mathbf{e}$ & $27,83 \mathbf{c d}$ & $66,90 \mathbf{a}$ & $66,53 \mathbf{a}$ \\
\hline Twins Row & 24,43 bc & $28,93 \mathbf{a b}$ & $66,77 \mathbf{a}$ & $66,60 \mathbf{a}$ \\
\hline Twins Seeds & 24,23 bcd & $29,03 \mathbf{a b}$ & $67,33 \mathbf{a}$ & $67,03 \mathbf{a}$ \\
\hline Kedelai & 23,90 bcde & 28,53 bc & $67,63 \mathbf{a}$ & \\
\hline Tumpangsari & & & & \\
\hline Sigle Row & 43,03 cde & $27,40 \mathbf{d}$ & $67,03 \mathbf{a}$ & $66,57 \mathbf{a}$ \\
\hline Doble Row & $25,10 \mathbf{a b}$ & $28,67 \mathrm{~b}$ & $67,47 \mathbf{a}$ & $67,06 \mathbf{a}$ \\
\hline Twins Row & $26,30 \mathbf{a}$ & $29,40 \mathbf{a}$ & $68,50 \mathbf{a}$ & $68,36 \mathbf{a}$ \\
\hline Twins Seeds & 22,70 de & $27,70 \mathbf{d}$ & $67,53 \mathbf{a}$ & $66,97 \mathbf{a}$ \\
\hline Respon & $*$ & $*$ & tn & tn \\
\hline
\end{tabular}

Keterangan $: \operatorname{tn}=$ tidak nyata, $*=$ nyata pada taraf $5 \%, * *=$ nyata pada taraf $1 \%$. Angka yang diikuti dengan huruf sama tidak menunjukkan perbedaan nyata pada uji BNT $5 \%$.

Kelembaban Udara Harian (\%) Hasil sidik ragam menunjukkan bahwa tidak terdapat perbedaan nyata kelembaban udara harian (\%) yang terbentuk akibat perlakuan. Hal ini senada dengan hasil penelitian Wentasari dan Sesanti, (2017) bahwa terdapat respon tidak nyata pada kelembaban relatif dibawah, tengah, dan atas pertanaman akibat perlakuan sistem tanam jagung sigle row, doble row, twins row dan twins seed. Hal tersebut diduga bahwa perbedaan suhu yang diakibatkan oleh perlakuan tidak menyebabkan perbedaan kemampuan mengandung uap air di udara sehingga kelembaban relatif semua perlakuan sama. Perubahan suhu adalah faktor yang mengatur perubahan kelembaban relatif udara harian (Manik TK, 2012). Jumlah uap air diudara ditentukan oleh suhu udaranya, semakin tinggi suhu udara maka potensi mengandung uap air semakin meningkat (Handoko, 1993)

\section{Pertumbuhan Tanaman.}

Pertumbuhan Jagung Manis, perbedaan nyata respon perlakuan terdapat pada parameter diameter batang dan jumlah daun (Tabel 3). 
Tabel 3. Hasil Sidik Ragam Paramer Pertumbuhan Tanaman Jagung

\begin{tabular}{|c|c|c|c|c|}
\hline Perlakuan & $\begin{array}{l}\text { Tinggi Tanaman } \\
\text { (cm) }\end{array}$ & $\begin{array}{l}\text { Diameter } \\
\text { Batang } \\
(\mathbf{m m})\end{array}$ & $\begin{array}{l}\text { Jumlah } \\
\text { Daun } \\
\text { (Helai) }\end{array}$ & $\begin{array}{l}\text { Jumlah } \\
\text { Cabang } \\
\text { (cabang) }\end{array}$ \\
\hline \multicolumn{5}{|l|}{ Tanam Tunggal } \\
\hline Sigle Row & $160,10 \mathbf{a}$ & $26,13 \mathbf{a}$ & $9,20 \mathbf{a}$ & $8,57 \mathbf{a}$ \\
\hline Doble Row & $162,77 \mathbf{a}$ & 20,70 bc & $9,17 \mathbf{a b}$ & $8,23 \mathbf{a}$ \\
\hline Twins Row & $138,80 \mathbf{a}$ & 19,50 & $8,43 \mathbf{a b}$ & $7,33 \mathbf{a}$ \\
\hline Twins Seeds & $155,57 \mathbf{a}$ & $24,83 \mathbf{a b}$ & $9,03 \mathbf{a b}$ & $8,23 \mathbf{a}$ \\
\hline \multicolumn{5}{|l|}{ Tumpangsari } \\
\hline Sigle Row & $143,53 \mathbf{a}$ & $24,63 \mathbf{a b}$ & $8,87 \mathbf{a b}$ & $8,47 \mathbf{a}$ \\
\hline Doble Row & $161,47 \mathbf{a}$ & $24,40 \mathbf{a b}$ & $9,13 \mathbf{a b}$ & $8,00 \mathbf{a}$ \\
\hline Twins Row & $135,00 \mathbf{a}$ & 20,57 bc & $8,10 \quad \mathbf{b}$ & $7,80 \mathbf{a}$ \\
\hline Twins Seeds & $140,10 \mathbf{a}$ & 22,50 abc & $9,20 \mathbf{a b}$ & $7,57 \mathbf{a}$ \\
\hline Respon & tn & $*$ & $*$ & tn \\
\hline
\end{tabular}

Keterangan $: \operatorname{tn}=$ tidak nyata, $*=$ nyata pada taraf $5 \%, * *=$ nyata pada taraf $1 \%$. Angka yang diikuti dengan huruf sama tidak menunjukkan perbedaan nyata pada uji BNT $5 \%$.

Hasil uji lanjut BNT (5\%) menunjukkan bahwa terdapat perbedaan nyata diameter batang antar perlakuan tanam tunggal sigle row $(26,13 \mathrm{~mm})$ dengan tanam tunggal doble row $(20,70 \mathrm{~mm})$, tanam tunggal twins row $(19,50 \mathrm{~mm})$ dan Tumpangsari twins row $(20,57 \mathrm{~mm})$. Hal ini diduga disebabkan oleh kerapatan antar tanaman dalam baris pada perlakuan tanam tunggal twins row $(20 \times 10 \times 80 \mathrm{~cm})$ dibandingkan dengan tanam tunggal sigle row $(75 \times 25 \mathrm{~cm})$ menyebabkan tanaman jagung pada Tanam Tunggal doble row, Tanam tunggal twins row dan tumpangsari twins seeds menunjukkan gejala etiolasi. Pada kerapatan rendah menyebabkan pemanfaatan sumberdaya lingkungan tidak maksimal akan tetapi pada kerapatan tinggi menyebabkan tingkat kompetisi tinggi sehingga pertumbuhan individu terhambat. Menurut Fatchullah, (2017) bahwa penggunaan kerapatan tanaman pada dasarnya untuk memberikan ruang serta pertumbuhan tanaman yang baik tanpa mengalami persaingan tanaman. Perbedaan antar perlakuan juga terjadi pada parameter jumlah daun, terdapat perbedaan nyata antara perlakuan jumlah daun pada tanam tunggal sigle row $(9,20$ helai) dengan perlakuan Tumpangsari Twins Row (8,10 helai). Dimana berdasarkan rata-rata jummlah daun pada tanam tunggal sigle row merupakan jumlah daun terendah dan jumlah daun tumpangsari twins row. Senada dengan parameter lain bahwa perbedaan nyata pada parameter jumlah daun disebabkan oleh kerapan populasi yang tinggi pada perlakuan tumpangsari twins row. Hal ini sejalan dengan hasil penelitian Bunyamin $\mathrm{Z}$ dan Awaluddin, (2013) bahwa varietas jagung sri kencana memilki rata-rata jumlah daun lebih sedikit 8 helai pada jarak tanam 50 x $20 \mathrm{~cm}$ dibandingkan pada jarak tanam $60 \times 20 \mathrm{~cm}$ dan $70 \times$ 20 helai yaitu 9 helai.

Pertumbuhan Kedelai. Berdasarkan rata-rata parameter pertumbuhan menunjukkan bahwa Tinggi Tanaman $(\mathrm{cm})$, Diameter Batang $(\mathrm{mm})$, Jumlah Daun $(\mathrm{cm})$ dan Jumlah Cabang (cabang) Tumpangsari dibawah rata-rata tanam tunggal kedelai. (Tabel 3). Akan tetapi bila dilihat dari hasil sidik ragam menunjukkan bahwa tidak terdapat perbedaan yang nyata pengaruh perlakuan terhadap semua parameter produksi pada tanaman kedelai. Dengan demikian tanaman kedelai dapat tumbuh dengan baik pada tumpangsari dengan sistem tanam jagung sigle row, doble row, twins row, dan twins seed. Penataan tanaman jagung dalam sistem tumpangsari dengan tanaman lain perlu dilakukan agar kompetisi antar tanaman dalam memanfaatkan hara, menggunakan radiasi matahari dan ruang tumbuh tidak berakibat buruk bagi hasil (Nurmas, 2011) 
Wentasari, R dan Gusta, AR: Karakteristik Iklim Mikro Serta Pertumbuhan Pada Beberapa Sistem .....

Tabel 3. Hasil Sidik Ragam Paramer Pertumbuhan Tanaman Kedelai

\begin{tabular}{|c|c|c|c|c|}
\hline Perlakuan & $\begin{array}{l}\text { Tinggi } \\
\text { Tanaman } \\
\text { (cm) }\end{array}$ & $\begin{array}{l}\text { Diameter } \\
\text { Batang } \\
(\mathbf{m m})\end{array}$ & $\begin{array}{l}\text { Jumlah } \\
\text { Daun } \\
\text { (cm) }\end{array}$ & $\begin{array}{l}\text { Jumlah } \\
\text { Cabang } \\
\text { (cabang) }\end{array}$ \\
\hline \multicolumn{5}{|l|}{ Tumpangsari } \\
\hline Sigle Row & $38,78 \mathbf{a}$ & $4,99 \mathbf{a}$ & $10,13 \mathbf{a}$ & $1,88 \mathbf{a}$ \\
\hline Doble Row & $45,11 \mathbf{a}$ & $4,90 \mathbf{a}$ & $10,77 \mathbf{a}$ & $2,00 \mathbf{a}$ \\
\hline Twins Row & $37,43 \mathbf{a}$ & $4,83 \mathbf{a}$ & $9,22 \mathbf{a}$ & $1,44 \mathbf{a}$ \\
\hline Twins Seeds & $37,42 \mathbf{a}$ & $5,12 \mathbf{a}$ & $9,47 \quad \mathbf{a}$ & $1,44 \mathbf{a}$ \\
\hline Tanam Tunggal & & & & \\
\hline Kedelai & $40,43 \mathbf{a}$ & $5,73 \mathbf{a}$ & $11,43 \mathbf{a}$ & $2,23 \mathbf{a}$ \\
\hline
\end{tabular}

Keterangan : tn $=$ tidak nyata, $*=$ nyata pada taraf $5 \%, * *=$ nyata pada taraf $1 \%$. Angka yang diikuti dengan huruf sama tidak menunjukkan perbedaan nyata pada uji BNT $5 \%$.

Terdapat pengaruh positif tumpangsari dibandingkan tanam tunggal, antara lain: 1) terjadi peningkatan efesiensi lahan, tenaga kerja, dan pemanfaatan radiasi matahari, 2) populasi tanaman dapat diatur sesuai yang dikehendaki, 3) dalam satu areal diperoleh produksi lebih dari satu komoditas, 4) tetap mempunyai peluang mendapatkan hasil manakala satu jenis tanaman yang diusahakan gagal, dan 5) kombinasi beberapa jenis tanaman menciptakan stabilitas biologis. (Handayani, 2011)

\section{KESIMPULAN DAN SARAN}

Karakteristik iklim mikro pada sistem tanam jagung sigle row, doble row, twins row dan twins seeds dengan tanam tunggal dan tumpangsari jagung kedelai adalah Intersepsi Cahaya (\%) pada pagi bagian tengah tajuk tanaman, siang dan sore pada bagian tengah dan bawah tajuk tanaman tidak memberikan respon nyata terhadap perlakuan; Suhu Harian (oC) terdapat perbedaan nyata suhu harian akibat perlakuan dan terdapat perbedaan nyata suhu harian antar perlakuan dimana perlakuan tumpangsari twins seed memiliki rata-rata suhu yang tertinggi dibagian bawah tajuk tanaman $(26.30 \mathrm{oC})$ dan dibagian tengah tajuk tanaman $(29,40$ oC); dan Kelembaban Udara Harian (\%) tidak memberikan respon berbeda nyata akibat perlakuan. Pertumbuhan kedelai tidak memberikan respon nyata terhadap perlakuan sedangkan pertumbuhan jagung memberikan respon nyata pada parameter diameter batang dan jumlah daun

Tanaman kedelai memiliki potensi untuk dikembangkan dalam tumpangsari dengan sistem tanam jagung doble row, twins row, dan twins seed dan diperlukan penelitian lebih lanjut untuk mendapatkan jarak lorong antar jagung terbaik pada tumpangsari doble row, twins row dan twins seed untuk menciptakan iklim mikro dan pertumbuhan tanaman yang lebih kondusif.

\section{UCAPAN TERIMA KASIH}

Penulis mengucapkan terima kasih kepada Direktorat Riset dan Pengabdian Masyarakat, Kementerian Riset, Teknologi, dan Pendidikan Tinggi, atas pendanaan kegiatan ini melalui skim Penelitian Dosen Pemula tahun 2017.

\section{DAFTAR PUSTAKA}

Bunyamin. Z and Aqil, M. (2010) 'Analisis Iklim Mikro Tanaman Jagung', in Proseding Pekan Serelia Nasional, pp. 978-979.

Fatchullah, D. (2017) 'Pengaruh Kerapatan Tanaman terhadap Pertumbuhan dan Hasil Benih Kentang (Solanum Tuberosum L.) Generasi Satu (G1) Varietas Granola', Planta Tropika: Journal of Agro Science. doi: 10.18196/pt.2017.067.15-22. 
Handayani, A. (2011) 'Pengaruh model tumpang sari terhadap pertumbuhan dan hasil tanaman gandum dan tembakau', Jurnal Widyariset, 14(3), pp. 479-488.

Handoko (1993) Klimatologi Dasar Landasan Pemahaman fisika atsmosfer dan unsur unsur iklim. Bogor: Jurusan Geofisika dan meteorologi FMIPA-IPB.

Indrawan, R. R., Suryanto, A. and Soeslistyono, R. (2017) 'Kajian iklim mikro terhadap berbagai sistem tanam dan populasi tanaman jagung manis (Zea mays saccharata Sturt.)', Jurnal Produksi Pertanian, 5(1), pp. 92-99.

Manik TK (2012) Klimatologi Dasar Unsur Iklim dan Proses Pembentukannya. Yogyakarta: Graha Ilmu.

Nurmas, H. A. (2011) 'Kajian waktu tanam dan kerapatan tanaman jagung sistem tumpangsari dengan kacang tanah terhadap nilai ler dan indeks kompetisi’, Agriplus, 21(1), pp. 61-67.

Sesanti Rizka Novi et al. (2014) 'Perbandingan Pertumbuhan dan Produksi Jagung Manis (Zea Mays Saccharata L ) pada Sistem Tanam Satu Baris dan Dua Baris', Agrovigor.

Slamet B (2008) 'Iklim Mikro Bagi Tegakan Hutan. Karya Ilmiah', Fakultas Kehutanan Universitas Sumatera Utara.

Tjasyono, B. (2004) Klimatologi. Bandung: ITB.

Wentasari, R. and Sesanti, R. N. (2017) 'Karakteristik Iklim Mikro Dan Produksi Jagung Manis Pada Beberapa Sistem Tanam', Jurnal Penelitian Pertanian Terapan. doi: 10.25181/jppt.v16i2.100.

Z, B. and Awaluddin (2013) 'Pengaruh Populasi Tanaman Terhadap Pertumbuhan dan Hasil Jagung Semi ( Baby Corn )', Seminar Nasional Serealia. 